\title{
EL OBRERISMO ORGANIZADO EN LAS CUENCAS MINE- RAS DE LEÓN (1918-1923)
}

\author{
JosÉ L. MARTÍNEZ CELADA
}

\section{Resumen}

El incremento coyuntural de las exportaciones españolas de carbón al abrigo de la I Guerra Mundial modificó de manera súbita tanto la propia producción como las relaciones laborales en el seno de las explotaciones. En medio de un ambiente muy caldeado en el que las exigencias patronales no correspondían a las compensaciones dadas a los trabajadores el conflicto social parecía inevitable.

En la provincia de León el sindicalismo de clase conoció un auge sin precedentes que consolidó a los mineros como su más fuerte baza en la zona. Las sociedades mineras adscritas a la UGT, aun conociendo fluctuaciones en cuanto a su nivel de afiliación o arraigo estructural, coparon la presencia minera hasta el advenimiento de la II República. Las oportunistas sociedades confesionales tuvieron carácter hegemónico en determinados sitios, fracasando en sus intentos de captación de nuevos adeptos fuera de su ámbito natural.

\section{Palabras clave}

Sindicato Minero, sección, asociación, catolicismo social, patronal, posguerra, crisis, tercerismo.

\begin{abstract}
As one of the biggest derivations of the Great War in Spain could be noted the increased exportation of coal. Connected with it Northern León developed on a strong working-class, whose primary organization had been weak. Thus, between owners requirements in order to increase the productivity and a critical way of life, the labour unionism was the lone answer to solve the juncture. At last, the social context became more complicated due to unions internal scissions.
\end{abstract}

\section{Key words}

Strike, mining, trade-union, social-struggle, wage, standard of living, political breakdown.

\section{INTRODUCCIÓN}

La expansión definitiva del obrerismo organizado en España se produjo a partir de la segunda década del siglo XX, coincidiendo entonces varios factores que le dieron categoría de auténtico movimiento de masas. 
El panorama de encuadre vino definido por una acentuada complejidad de las relaciones laborales que darían como resultado una creciente contestación en el medio, pronto convertida en un problema social de primer orden, en el cual las derivaciones económicas y laborales no eran, frecuentemente, lo más importante.

La Unión General de Trabajadores reactivó su práctica sindical en base a una ordenación orgánica nueva, en la que la que los sindicatos de industria habrían de sustituir progresivamente a los de oficio. Por otro lado, se asistía a una cierta renovación ideológica que partía de una progresiva politización y un pragmatismo radical que, enraizado en el ideario pablista, hacía primar la consecución de exigencias laborales a corto plazo sobre un horizonte revolucionario alejado e intangible. Todo ello estaría sometido a un organigrama burocratizado, estrictamente jerarquizado, que no hacía concesión alguna a la improvisación. Con estas premisas el gran salto de la Unión General se habría de plasmar en una tupida red de secciones con un espíritu globalizador, es decir, incluir al máximo número de trabajadores en todos los lugares y sectores en los que fuese posible.

Tabla I. Efectivos de la Unión General de Trabajadores (1910-1922) ${ }^{1}$

\begin{tabular}{|l|c|c|}
\cline { 2 - 3 } \multicolumn{1}{c|}{} & Secciones & Afiliados \\
\hline Junio-1910 & 305 & 40.984 \\
\hline Enero-1913 & 351 & 147.729 \\
\hline Febrero-1916 & 138 & 76.304 \\
\hline Julio-1918 & 457 & 89.601 \\
\hline Mayo-1920 & 1.078 & 211.342 \\
\hline Septiembre-1922 & 1.198 & 208.170 \\
\hline
\end{tabular}

El segundo gran hito renovador del contexto obrerista fue la constitución de la Confederación Nacional del Trabajo en 1910. Aglutinó a diversos sectores que unieron sus esfuerzos en un sindicalismo revolucionario considerado "como un medio de lucha entre los dos antagónicos intereses de clase". La maleable estructura confederal predisponía a la acción decidida $\mathrm{y}$, en ocasiones, inconsciente, planteando un modo de entender la lucha de clases que nada tenía que ver con el oportunismo de la UGT.

Ambos modelos eran antagónicos y raramente conciliables en torno a planteamientos comunes, aunque, como máxima indiscutible, compartían la defensa de los intereses de los trabajadores por ellos mis-

\footnotetext{
${ }^{1}$ Memoria del XV Congreso ordinario de la Unión General de Trabajadores. Madrid, 1922.
} 
mos, sin entrometidos interesados. Esta fue la gran diferencia de origen entre un sindicalismo de clase honrado (al margen de interpretaciones sobre acción o estrategias coyunturales) y un pseudosindicalismo al servicio de la patronal que también habría de encontrar cierto desarrollo en la época.

El sindicalismo católico posiblemente tuvo una concepción teórica inicial de defensa sana de los trabajadores con fundamento principios de armonía y hermandad. No obstante, la degradación del armado ideológico primitivo fue tan acelerado que pronto el obrerismo católico no era más que un mero instrumento dentro de la táctica de combate planteada por la patronal contra el desarrollo del sindicalismo de clase. El Marqués de Comillas financió el sindicalismo católico en los sectores mineros e industrial con una clara vocación contrarrevolucionaria.

El contexto era más complejo que nunca. El estallido de la I Guerra Mundial y las consecuencias derivadas para España agravaron esa complejidad, renovándose tácticas en medio de la crisis. Las exigencias económicas y la conexión consiguiente entre realidad social, obsceno acaparamiento especulativo e incapacidad gubernamental, formaron un conglomerado en el que las organizaciones sindicales habían de asumir, más que nunca, su responsabilidad.

\section{EL ACERCAMIENTO DE LOS MINEROS LEONESES A LA UNIÓN GENERAL EN UNA ETAPA CRÍTICA}

La debilidad de la organización sindical entre los mineros de la provincia venía arrastrándose desde que las cuencas comenzaron a explotarse. Nunca se había ido más allá de un asociacionismo de corte mutualista tradicional. El interés por la inclusión de los obreros mineros dentro del obrerismo organizado fue percibido por la Unión General de Trabajadores que habría de reservar un espacio destacado para ellos dentro del sindicato. El replanteamiento interno en torno a agrupaciones de industria de base múltiple fue tomada en el X Congreso general celebrado en 1910, siendo los primeros en establecerse el ferroviario ("Unión Ferroviaria"), el minero (Federación Nacional de Mineros) y el textil (Federación Textil).

Las nuevas federaciones de industria fueron la clave de la expansión ugetista de la segunda década del siglo XX. Además el monopolio en la representación de los trabajadores, ejercido por un determinado 
sindicato de clase, tenía una clara relación geográfica, por lo que en regiones de control de la UGT era difícil el arraigo de la CNT y viceversa. La provincia de León se incluía dentro de las zonas de preponderancia de la Unión, siendo la que contó con el apoyo mayoritario de los obreros organizados.

Con el nuevo marco de relaciones internas proporcionado por el obrerismo socialista todo parecía preparado para facilitar la entrada a los mineros de las cuencas leonesas. Sin embargo, su implantación tuvo un retraso considerable. Ni la constitución de la Federación Minera en 1911 ni la permanente influencia del Sindicato de Obreros Mineros de Asturias pudieron establecer una red firme de secciones hasta bien entrada la década, esencialmente después de los sucesos de 1917.

El I Congreso de la Federación Minera de la Unión General tuvo lugar en mayo de 1913 sin representación de los mineros leoneses. El contingente minero había pasado de 464 federados en junio de 1910 a 11.383 con motivo de ese primer congreso ${ }^{2}$. Los progresos eran evidentes a raíz de la creación de la Federación, aunque el potencial de la masa minera leonesa estaba todavía sin explotar.

En la provincia los pasos dados fueron lentos y relativamente inversos a lo normal. Aquí, el conflicto daría paso a la organización y no, como sucedía por ejemplo en Asturias, éste se sustentaría en una sólida estructura ya consolidada. Obviamente esta vía retrasó su ordenación al estar conectada casi exclusivamente con coyunturas críticas que forzaban la agrupación.

Las consecuencias directas del estallido de la Gran Guerra dieron el empujón definitivo a la extensión ugetista. El retraso acumulado era considerable con respecto a otras cuencas, pero en aquel momento rápidamente se pondría a la altura.

Antes de Agosto de 1917, y ya inmersos un ciclo infernal de aumento de exigencias productoras sin base firme, los conflictos laborales en las cuencas mineras fueron frecuentes. Las exigencias planteadas tenían relación con el aumento de salario y la mejora general de las condiciones de trabajo ${ }^{3}$, aunque progresivamente se iba haciendo especial in-

\footnotetext{
2 Datos procedentes de La Unión Obrera, junio de 1910, y El Socialista, 17 de mayo de 1913.

${ }^{3}$ Como uno de los muchos ejemplos en torno a exigencias salariales se puede citar el exitoso paro de dos días (7 y 8 de febrero de 1916) que según las estadísticas oficiales plantearon los 17 mineros del pozo "Mercedes" de Matallana de Torío. Estadística de Huelgas. Años 1915-1916. Instituto de Reformas Sociales.
} 
cidencia en el reconocimiento de la personalidad sindical como auténtica representación de los obreros. Con ello se trastocaban las relaciones laborales, tal y como se habían entendido tradicionalmente, tendiéndose a la confrontación patronal-trabajadores en igualdad de condiciones. Quizá el más conocido en este sentido fue el paro del pozo "La Competidora" de Santa Lucía en 1916 que necesitó la mediación de Gumersindo Azcárate para resolver el conflicto. No fue el único, puesto que un año antes en Pola de Gordón un grupo de obreros de la Vasco-Leonesa se había declarado en huelga para que se reconociera su derecho de asociación ${ }^{4}$.

Por entonces las campañas propagandísticas precedentes estaban dando sus primeros frutos. Con Agustín Marcos como elemento dinamizador desde la cuenca de Gordón, la irradiación del Sindicato Minero Leonés respondería al mismo modelo que el asturiano. Manuel Llaneza había dotado al SOMA de un espíritu reivindicativo legalista, oponiendo la consecución de éxitos parciales a corto plazo a la posibilidad de alcanzar exigencias maximalistas a través de la lucha obrera. Por el momento era una táctica suficiente para satisfacer a las bases, pero cuando la crisis socioeconómica de posguerra se generalizó el pragmatismo llanecista ya no fue suficiente, haciéndose notar una oposición interna más radical que acabaría por escorar a posiciones comunistas.

Con todo, el modelo reformista de Llaneza fue el que se extendió por las cuencas leonesas. Coincidiendo con la expansión de la Unión, tuvo lugar la Huelga General de Agosto que, en el terreno en el que nos movemos, serviría para fortalecer las perspectivas de crecimiento en la provincia. Fundamental a la hora de afianzar la red sindical en un momento crítico fue la postura tomada por la dirección minera asturiana, trasmutada con urgencia a las cuencas leonesas. El "cruzamiento absoluto de brazos" se impuso como la estrategia de los mineros durante la huelga de agosto; las desviaciones revolucionarias, más o menos radicales, no encontraron demasiado eco.

El paro de los mineros leoneses comenzó el 14 de agosto y concluyó, sin apenas incidentes el día 17. Las acciones más destacadas tuvieron relación con el corte de las vías del Hullero. Desde Matallana de Torío a Puente Almuhey el transporte ferroviario estuvo paralizado. La vuelta a la normalidad se produjo por propia iniciativa de los mineros, aunque la coactiva presencia de las fuerzas del orden hubo de forzar su

${ }^{4}$ Ibídem. 
intención en ese sentido ${ }^{5}$. Las múltiples consecuencias del movimiento de agosto no pasaron, sin embargo, por el declive del obrerismo organizado. Una doble reacción de diferente signo entró en conflicto desde 1918.

Pese a que los ambiciosos objetivos de la huelga fracasaron, el discreto compromiso de muchos cuadros dirigentes hizo que la estructura perdurase en tiempos de represión y ajuste de plantillas ${ }^{6}$. Además se extendió la idea de la agrupación obrera como mejor vía de defensa colectiva. Ambas circunstancias respaldaron la propagación de la Federación minera de la Unión en plena crisis de posguerra.

La campaña propagandística de la Unión General encontró en la mezcla de impulsos el principal argumento que debía apoyar su desarro1lo. Por un lado, la amnistía de los encarcelados por los sucesos de agosto se convertía en el elemento sentimental, por otro, la galopante crisis económica que ponía en peligro un nivel mínimo de subsistencia constituyó el aspecto más concreto. Junto al crédito alcanzado por la Unión entre los mineros por su postura durante el movimiento de agosto, todo era favorable para enraizarse definitivamente en las cuencas mineras de León ${ }^{7}$.

Los paros parciales por motivos estrictamente laborales fueron muy frecuentes a lo largo de 1918. Generalmente con resultados positivos para los trabajadores, habrían de ser una motivación más para que creciera la Unión en base a secciones locales. En las cuencas de Gordón, núcleo fundamental del Sindicato Minero Leonés, y Sabero-Cistierna las huelgas se sucedieron involucrando a cientos de obreros mineros.

Particular interés y repercusión tuvieron los largos paros en las explotaciones saberenses. Allí, como sucedería poco después en el Bierzo o Laciana, las razones puramente laborales se mezclaban con una dura pugna entre los ugetistas y los propagandistas comillistas.

Durante 23 días, del 13 de agosto al 5 de septiembre, los mineros

\footnotetext{
5 Para conocer algo más en profundidad los hechos que acontecieron alrededor de la huelga de agosto y su relación la Unión se puede consultar REDERO SANROMÁN, M. (coord.), Historia de la Unión General de Trabajadores en Castilla y León (en preparación).

${ }^{6}$ El más destacado ejemplo fue el del SOMA y sus dirigentes que nunca creyeron en un movimiento revolucionario, cuidándose mucho de comprometerse totalmente. Esta falta de compromiso, además de su potencia indudable, evitó las represalias de la patronal a modo de depuración de plantillas tal y como sucedió entre los seleccionados del ferrocarril.

${ }^{7}$ Desde una postura de parcialidad, veáse por ejemplo la información aportada por Germán Iglesias, presidente de las Juventudes Socialistas de Santa Lucía, sobre los progresos de la organización de la Unión en la cuenca gordonesa. "Los mineros leoneses". El Socialista, 30 de agosto de 1918.
} 
de la Compañía Oeste de Sabero sostuvieron un paro que, entre otras cosas, debía acarrear el relevo del capataz-contratista por parte de la empresa. La consecución de los objetivos pretendidos mereció una crónica en El Socialista.

"Estos obreros, que estaban en condiciones iguales a las de todo el valle de Sabero, merced a su unión y gran disciplina han conseguido también un aumento en sus jornales de 25 céntimos (...); también consiguieron estos compañeros la readmisión de un compañero despedido antes del conflicto, como igualmente la creación de una cooperativa, para la cual la Empresa adelanta de ocho a doce mil pesetas" 8 .

Dentro del mismo conflicto, los 46 huelguistas de la Compañía Fausta de Veneros continuaron irreductibles ante la intransigencia de la patronal a cesar a su capataz. La capacidad de resistencia se puso a prueba: la propia debilidad (por incipiente) de la Unión en la cuenca vino a unirse a la presión de los amarillos que fomentaban la sustitución de los huelguistas por mano de obra dócil.

La segunda gran movilización en la zona la plantearon 836 mineros de las Hulleras de Sabero del 12 de diciembre de 1918 al 4 de enero de 1919. Los objetivos eran forzar un aumento de salario y que se reconociera la jornada de 8 horas de trabajo. Fue ganada parcialmente al fijarse un salario medio más alto pero no lograrse un horario de trabajo rebajado 9 . Aunque ambas de carácter laboral, el reconocimiento de la jornada legal de 8 horas encerraba connotaciones de carácter político que habrían de esperar algo más para ser contempladas por la autoridad.

En medio de una ola de huelgas en las minas de la provincia, el Sindicato Minero Leonés acudió al II Congreso de la Federación de Mineros de la Unión en representación de 3000 afiliados. Celebrado del 11 al 13 de octubre, al poco de la clausura del XIII Congreso general de la UGT, Agustín Marcos fue el delegado en el importante conclave.

Con una orientación claramente reformista en todas las resoluciones tomadas (salario mínimo, jornada laboral, condiciones de trabajo) y siempre abierto a una hipotética actualización de la estructura con el fin de encarar mejor los retos cotidianos, el Congreso de los mineros había seguido fielmente la nueva orientación tomada en el Congreso ordinario

\footnotetext{
8 El Socialista, 7 de septiembre de 1918.

9 Según las cifras oficiales, de los 856 empleados en las explotaciones 836 fueron a la huelga lo que nos remite al grado de concienciación sobre los objetivos planteados. Estadística de huelgas. Año 1918. Instituto de Reformas Sociales.
} 
de la UGT. Las veleidades revolucionarias quedaron definitivamente apartadas, con lo que se afirmaba el legalismo largamente pregonado desde la organización minera.

Tabla II. Sindicatos representados en el II Congreso de la Federación de Mineros ${ }^{10}$

\begin{tabular}{|l|c|}
\cline { 2 - 2 } \multicolumn{1}{c|}{} & Afiliados \\
\hline Asturias & 15.000 \\
\hline Peñarroya & 7.500 \\
\hline Riotinto & 4.000 \\
\hline León & 3.000 \\
\hline Vizcaya & 1.500 \\
\hline Palencia & 1.200 \\
\hline Linares & 200 \\
\hline Puertollano & 1.600 \\
\hline Llano del Beal & 1.300 \\
\hline TOTAL & $\mathbf{3 5 . 3 0 0}$ \\
\hline
\end{tabular}

En el bienio 1918-1919, el Sindicato Minero Leonés estaba en pleno crecimiento antes de que se viese enormemente afectado por la querella comunista. Agustín Marcos coordinaría la expansión cuyos requisitos eran: propaganda y estable constitución de sus secciones, es decir, que fuesen capaces de sostenerse en periodos críticos para lo cual deberían de contar con una saneada caja de resistencia y con un organigrama en el que cada miembro tuviera estricto conocimiento de su labor. Como ocurriera de la cúspide a la base del sindicato socialista, todo giraba alrededor de la previsión y rigorismo del aparato.

En las cuencas de la Montaña Central (Gordón y Torío) los cuadros formados bajo el impulso asturiano fueron los más dinámicos de la provincia: Ramón Herrera, Saturnino Portugués, Gabriel Díez y Narciso Blanco en Santa Lucía; Gonzalo Tapia y León Carrasco en La Robla. Los intentos de los propagandistas católicos por penetrar en estas zonas de monopolio ugetista siempre fueron infructuosos. No ocurrió lo mismo en la montaña oriental y occidental; en ambos sectores el potencial del asociacionismo católico era considerable, por lo que las dificultades fueron mayores.

En la cuenca de Sabero-Cistierna la tardía implantación se consolidó por medio, como vimos arriba, de la lucha reivindicativa que dejó en evidencia el pretendido ideario social-católico de los amarillos. De cual-

${ }^{10}$ El Socialista, 11 de octubre de 1918. 
quier modo, el antagonismo a todos los niveles entre los sectores conservadores y progresistas fue una de las constantes en la zona hasta la II República, mostrando un entramado sociolaboral bastante más complejo que en otros lugares.

En el Bierzo y Laciana la penetración de la Unión se hizo en condiciones de inferioridad con respecto a las asociaciones católicas. El patrocinio de la patronal a los amarillos dificultaba la organización ugetista que, tras un comienzo complicado, abanderaría en León la resistencia en los complicados años de la escisión. El 19 de septiembre de 1919 quedó constituida la sección de Ponferrada del Sindicato Minero Leonés con Leoncio Sanz y Luis Garrote a la cabeza; en Laciana hubo que esperar a 1920 para que se implantase con la constitución de las secciones de San Miguel y Caboalles de Abajo. Félix Galán en sus crónicas para El Socialista rememoró los tiempos difíciles:

"La principal empresa es la Minero Siderúrgica de Ponferrada, a la que siguen varios grupos de menor implantación. (...) Como todas las cuencas de nueva implantación, por lo heterogéneo del personal que a ella acude, fue ésta apetecible por los amarillos, que durante algún tiempo contribuyeron a entorpecer el avance del sindicato, apelando en ocasiones a vituperables actos de violencia"11.

En 1920 el Sindicato Minero Leonés era el representante legal de la mayoría de los obreros mineros de la provincia. Atendiendo a las cifras dadas por la Unión en las memorias de su XIV Congreso general, sus afiliados se encontraban en casi todas las explotaciones, desde el Bierzo a Sabero-Cistierna, aunque perduraban zonas en las que la penetración resultaba casi imposible ${ }^{12}$.

Días antes de la inauguración del Congreso en la que la Unión habría de tocar techo, se había clausurado el III Congreso de la Federación Nacional de Mineros. En la asamblea de los mineros se apreciaba desde el primer momento su potencial:

“Asturias, Peñarroya, Vizcaya y León, con otras cuencas mineras de menos importancia, constituyen las falanges más aguerridas de la UGT. Los

\footnotetext{
11 “El valle de Laceana”. A través de la España Obrera: notas informativas recogidas en las excursiones de propaganda por los enviados del Partido Socialista y la Unión General de Trabajadores. Recopilación de las crónicas recogidas en El Socialista. Madrid, 1930, pp.110-112.

12 En las explotaciones de la zona de Puente Almuhey-Prado de la Guzpeña el monopolio católico motivó que hasta 1930 no se pudiesen establecer las secciones ugetistas en torno al Sindicato Minero Castellano. Retomando una tradición socialista que partía de principios de siglo ("La Aurora" de Prado de la Guzpeña), las secciones pioneras fueron las de Cerezal de la Guzpeña y Valderrueda.
} 
38.136 obreros que constituyen el organismo federativo, puestos en movimiento, pueden paralizar la vida nacional. Por eso los acuerdos que salgan de este recinto encierran una enorme trascendencia (...)"13.

Tabla III. Secciones mineras de la UGT en la provincia de León ${ }^{14}$.

\begin{tabular}{|c|c|c|c|}
\hline \multicolumn{2}{|l|}{1920} & \multicolumn{2}{|l|}{1922} \\
\hline Localidad & Afiliados & Localidad & Afiliados \\
\hline Argovejo & 62 & Caboalles de Abajo & 86 \\
\hline Aviados & 28 & Llombera & 58 \\
\hline Camposolillo & 90 & Orallo & 107 \\
\hline Cistierna & 180 & Piedrafita de Babia & 69 \\
\hline Coladilla & 15 & Rioscuro de Babia & 36 \\
\hline Granja de San Vicente & 69 & S. Miguel de Laciana & 120 \\
\hline Llombera & 50 & Sta. Cruz de Montes & 49 \\
\hline Matallana de Torío & 121 & Sta. Lucía de Gordón & 403 \\
\hline Olleros de Sabero & 550 & Vega de Gordón & 46 \\
\hline Orzonaga & 120 & La Vid & 60 \\
\hline Ponferrada & 267 & Villaseca de Laciana & 322 \\
\hline La Robla & 222 & \multirow[b]{2}{*}{ TOTAL } & \multirow[b]{2}{*}{1.356} \\
\hline Sabero & 160 & & \\
\hline Saelices de Sabero & 108 & & \\
\hline S. Miguel de Laciana & 24 & & \\
\hline Sta. Lucía de Gordón & 942 & & \\
\hline Santibáñez & 85 & & \\
\hline La Silva & 74 & & \\
\hline Torre del Bierzo & 112 & & \\
\hline La Valcueva & 128 & & \\
\hline Vega de Gordón & 179 & & \\
\hline Veneros & 200 & & \\
\hline La Vid & 212 & & \\
\hline TOTAL & 3.998 & & \\
\hline
\end{tabular}

Las propuestas del Sindicato Minero Leonés iban encaminadas hacia la mejora íntegra de las condiciones laborales, de acuerdo con la corriente general de acción. Con todo, las primeras disensiones internas ya se vislumbraban; pronto las reivindicaciones sobre salarios, accidentes del trabajo, comedores y aseos,... tendrían que compartir protagonismo con la urgencia de salvar a la estructura en plena crisis.

\footnotetext{
${ }^{13}$ El Socialista, 22 de junio de 1920.

${ }^{14}$ Memorias del XIV y XV congresos generales de la Unión General de Trabajadores.
} 


\section{EL SINDICALISMO CATÓLICO Y LA PATRONAL MINERA}

De forma paralela al desarrollo de la UGT con posterioridad al movimiento de agosto de 1917, se inició una campaña contrarrevolucionaria que desde todos los resortes disponibles intentaba ganarse la confianza de los trabajadores. El Secretariado Ferroviario y Minero fue el instrumento más directamente relacionado con esta expansión.

Las intenciones del Marqués de Comillas, gran impulsor y financiador del asociacionismo católico, partían de un principio muy claro que era ajeno a cualquier formulación teórica: contrarrestar el avance de los sindicatos de clase como fuese, no desechando para ello la utilización interesada de coartadas ideológicas que habrían de revestir de cierta profundidad a algo que era realmente plano.

En las asociaciones católicas de obreros mineros la defensa de los intereses de los trabajadores era algo secundario. De cualquier modo, en el seno de la estrategia planteada, las demandas de los asociados eran conectadas con el clásico paternalismo social-católico del "buen patrón".

En la provincia de León las campañas de propaganda de Aurelio Díaz y Agustín Ruiz comenzaron en las cuencas orientales inmediatamente después de la Huelga de Agosto. Los resultados no se hicieron esperar, pues las agrupaciones católicas creadas al calor del impulso reaccionario fueron numerosas.

La constitución en Cistierna de una sección del Sindicato Católico de Obreros Mineros fue el hito fundacional del comillismo en la provincia. Según se hizo constar en el registro que al efecto estaba en Gobierno Civil, el objeto que perseguía era la "defensa contra los abusos del capital"15. El activo núcleo de Cistierna consiguió que al poco tiempo fuese constituida otra agrupación subsidiaria en Santa Olaja de la Varga. La reacción católica en la zona se completó con la creación en noviembre de 1920 de agrupaciones juveniles en Crémenes y Sabero. El antagonismo ideológico radicalizado en la zona tuvo su origen en esta época, pudiendo ser rastreada su evolución hasta los sucesos revolucionarios de Octubre

\footnotetext{
${ }^{15}$ La perplejidad desde la que en la actualidad analizamos estos argumentos no era, sin embargo, claramente perceptible en la época, ya que originalmente, en el marco de un obrerismo poco concienciado y nada organizado, la demagogia era una vía muy frecuentada dada su utilidad para orientar a las masas obreras en uno u otro sentido.

La dirección de la sección estaba formada por Emilio Ruiz, presidente, Valentín Ruiz, vicepresidente, Fausto Baranilla, secretario, Esteban Tamayo, tesorero, y Segismundo Burón, contador. Véase Registro de Asociaciones. Libro 1. Archivo Histórico Provincial.
} 
de 1934.

La fundación en 1918 de la Minero Siderúrgica de Ponferrada supuso la explotación a gran escala de las cuencas occidentales de la provincia. Habiéndose hecho también con extensas concesiones en Laciana, se trazó de forma rapidísima el ferrocarril de vía estrecha entre la capital del Bierzo y Villablino para dar salida al carbón extraído.

Tabla IV. Secciones del Sindicato Católico de Obreros Mineros (1917-1921)

\begin{tabular}{|l|c|c|}
\hline Artículo II. Sección & $\begin{array}{c}\text { Presentación de Es- } \\
\text { tatutos }\end{array}$ & Artículo III. \\
\hline Cistierna & $19-\mathrm{X}-1917$ & $21-\mathrm{X}-1917$ \\
\hline Santa Olaja de la Varga & $4-\mathrm{II}-1918$ & $2-\mathrm{III}-1918$ \\
\hline Villaseca de Laciana & $12-\mathrm{VIII}-1918$ & $17-\mathrm{VIII}-1918$ \\
\hline Ponferrada & $24-\mathrm{XI}-1919$ & $28-\mathrm{XI}-1919$ \\
\hline Piedrafita de Babia & $30-\mathrm{XI}-1920$ & $7-\mathrm{XII}-1920$ \\
\hline Orallo & $14-\mathrm{V}-1921$ & -- \\
\hline Villablino & $19-\mathrm{V}-1921$ & $21-\mathrm{V}-1921$ \\
\hline Sosas de Laciana & $21-\mathrm{II}-1921$ & $2-\mathrm{III}-1921$ \\
\hline Boñar & $6-\mathrm{VII}-1921$ & -- \\
\hline Rioscuro & $15-\mathrm{X}-1921$ & $22-\mathrm{X}-1921$ \\
\hline
\end{tabular}

La coincidencia entre la necesidad de gran número de mano de obra y el momento convulso que se vivía, convenció a la empresa para fomentar la implantación entre su plantilla del asociacionismo católico. Tras asentarse en Villaseca de Laciana, el Sindicato Católico de obreros mineros se implantó en Ponferrada en noviembre de 1919, cuya cúpula directiva estaba compuesta por Bernardo Morala como presidente, Francisco Azpeicueta como tesorero y Bautista López como vocal. El núcleo comillista ponferradino se completaría un año más tarde con la constitución del Sindicato Católico Ferroviario, con lo que la docilidad de parte de la plantilla de la MSP, tanto en las explotaciones mineras como en sus infraestructuras ferroviarias, estuvo asegurada hasta mediados de la década de los años veinte.

Al mismo tiempo que se apreciaba la urgencia de contrarrestar el empuje del sindicalismo de clase por medio del establecimiento de organizaciones contrarrevolucionarias, la patronal sintió la necesidad de coordinar sus esfuerzos de forma global. En cuatro años el movimiento asociativo patronal fue considerable, aunque no siempre corrió en el mismo sentido: la presencia de varias organizaciones no era lo más pro-

\footnotetext{
${ }^{16}$ Registro de Asociaciones. AHP.
} 
picio una perfecta coordinación.

El llamado Sindicato Regional Minero Leonés fue la primera institución oficial de la patronal minera de la provincia. Constituida en diciembre de 1917, Sabas Martín Granizo y Pedro Gómez ostentaron su presidencia hasta que se disolvió en 1921. Su refundación con el nombre de Asociación Patronal de la Minería tuvo lugar en diciembre de ese mismo año. Con sede en la calle Fernando Merino (actual Calle Ancha), Manuel García, Pedro Gómez y Esteban Zuloaga coordinaron los intereses de parte de las empresas mineras de la provincia.

Con la Regional Minera todavía vigente, en octubre de 1918 la asociación patronal Mineros Leoneses se constituyó con el objeto de unir "minas y explotaciones"17. Para "fomentar la industria minera" en las cuencas occidentales se constituyó el 3 de noviembre de 1921 la Sociedad Minera del Bierzo presidida por Rafael Burgueño.

En plena crisis del sector en $1921^{18}$, los planes patronales se vieron favorecidos por un hecho imprevisto: la desviación comunista que, producida en el seno del socialismo español, acabaría por afectar al peso de la Unión en las cuencas. Por otra parte, y ya que el enemigo se debilitaba, no fue tan necesario potenciar a los amarillos, cuyas asociaciones también entraron en fuerte retroceso desde ese mismo año, no volviendo a asumir jamás el destacado papel adquirido durante esos años.

\section{LA FEDERACIÓN MINERA EN LEÓN: REORGANIZACIÓN Y ESCISIÓN}

A la vista de los datos que nos ofrece la tabla IV se aprecia un descenso notable de la afiliación ugetista en las cuencas leonesas entre 1920 y 1922. Las explicaciones no son sencillas, si bien la mayor parte de ellas pueden partir desde la interpretación de los movimientos internos dentro del socialismo español. En una etapa convulsa, de acentuada crisis económica, en la que la UGT había plegado sus estandartes políticos para refugiarse en el campo estrictamente laboral y el PSOE viraba hacia la socialdemocracia reformista, el influjo comunista vino a cuestionar el

\footnotetext{
${ }^{17}$ Con sede en la calle Cervantes, 10, de la capital de la provincia la dirección la componían Cayetano García, presidente, Bonifacio Rodríguez, vicepresidente, Alfredo Ladero, tesorero, Publio Suárez, secretario, Urbano Eggendeger, vocal, y Mario Campomanes, vocal. Registro de Asociaciones. AHP.

${ }^{18}$ En dos años económicos la producción anual de carbón en la provincia había descendido más de un $27 \%$, pasándose de 922 miles de toneladas en 1919 a 672 en 1921. El recorte de producción tuvo directa relación con el cierre de las explotaciones menos rentables nacidas al amparo de las necesidades eventuales de la coyuntura bélica.
} 
giro tomado.

La incidencia de la posterior escisión comunista afectó de un forma enorme al Partido Socialista y en menor medida a la Unión. El control que la Ejecutiva de Largo Caballero ejercía sobre todo el aparato motivó que las posturas terceristas fuesen siempre minoritarias y fácilmente derrotadas en cualquier proposición congresual. En este contexto, si había habido alguna federación que en los últimos años había crecido enormemente ésta era la minera. En consecuencia la cohesión alrededor del ideario ugetista era menor, percibiéndose una tendencia a la radicalidad sobredimensionada por la crisis del sector.

La respuesta de la Federación minera se anticipó a las consecuencias de la escisión comunista. La idea de reorganizar su estructura ya había sido tratada en el II Congreso de la Federación en 1918 a propuesta del delegado vizcaíno Egoechea. Entonces otras iniciativas más urgentes marginaron el debate. En 1920, en el III Congreso, las muestras de un posible desequilibrio interno eran más evidentes, por lo que se debían tomar las medidas oportunas. Era, como ya vimos, el momento cumbre de la Federación Minera en cuanto a número de afiliados, pero, desde otro punto de vista, también era el más peligroso debido a las tensiones derivadas del crecimiento. Los ajustes internos afectaron directamente al aparato de la Federación en la provincia: en el verano de 1920 la denominación "Sindicato Minero Leonés" dejaba de existir.

A propuesta de Manuel Llaneza el III Congreso de la Federación aprobó la fusión del Minero Leonés y el Minero Palentino, que cristalizaría en el Sindicato Minero Castellano. La medida estuvo claramente motivada por la creciente influencia de los terceristas entre las filas de los mineros leoneses y palentinos, no pretendiendo tanto retener afiliados descontentos como salvaguardar su implantación. Ante la disyuntiva de tolerar o no en su seno a elementos terceristas, la Federación Minera optó por abrirles con celeridad la puerta de salida. Se tendría que empezar casi de cero pero la salud de la organización siempre tuvo su diagnóstico más ligado a la lealtad de sus miembros que al índice de afiliación.

En el Sindicato Minero Palentino se observaba después del movimiento de Agosto una veloz propensión hacia posturas comunistas. En las cuencas palentinas (sobre todo en Barruelo de Santullán) los sucesos de agosto del 17 habían sido sensiblemente más violentos que en las leonesas. El incrementado componente de radicalidad se explicó entonces por el menor seguimiento que se hacía de la ortodoxia trazada desde el 
SOMA. Elementos locales habían dado unos tintes revolucionarios al movimiento ajenos al ideal llanecista, lo que derivó en más incidentes y, por consiguiente, en un aumento de la represión posterior.

En el bienio 1918-1920 la afiliación en Palencia se alimentó de la nueva corriente comunista y del aliciente sentimental proveniente de la represión del movimiento de agosto. En 1920, la sección de Barruelo de Santullán, la más potente del Minero Palentino (720 afiliados $-56 \%$ del total-), estaba en manos terceristas ${ }^{19}$.

La derrota de los partidarios de la III Internacional en el Congreso de la Unión dio píe a la depuración y la reorganización. En este sentido, Manuel Llaneza y Agustín Marcos desde León lo vieron claro: había que fortalecer a la Federación minera en base a ugetistas puros. Las desafección comunista fue encarada con decisión, aun a riesgo de acercar a la Unión al despeñadero en las cuencas leonesas.

Tabla V. Afiliados mineros a la UGT en León y Palencia ${ }^{20}$.

\begin{tabular}{|l|c|c|c|}
\cline { 2 - 4 } \multicolumn{1}{c|}{} & $\mathbf{1 9 2 0}$ & $\mathbf{1 9 2 2}$ & $\mathbf{1 9 2 3}$ \\
\hline S.M. Leonés & 3.998 & -- & -- \\
\hline S.M. Palentino & 1.290 & -- & -- \\
\hline S.M. Castellano & -- & 1.356 & 1.016 \\
\hline TOTAL & 5.288 & 1.356 & 1.016 \\
\hline
\end{tabular}

El Sindicato Minero Castellano concentró sus fuerzas en la provincia de León; su estructura en Palencia estaba prácticamente desbaratada. En las cuencas leonesas la merma fue considerable, manteniendo a duras penas la influencia preexistente. En León la crisis del sector desembocó en un importante movimiento huelguístico durante el verano de 1921, que habría de acarrear dos importantes consecuencias: En primer lugar, en el campo estrictamente sindical, se produjo cierto descontento entre los mineros organizados, muchos de los cuales optaron por abandonar la organización ante su incapacidad para sostener una postura firme. Además, el hundimiento de explotaciones marginales arrastraría un menor rendimiento global por minero (con la consiguiente rebaja de salarios

\footnotetext{
${ }^{19}$ Las proposiciones que fueron enviadas al XIV Congreso de la Unión en 1920 sirven de ejemplo del peso tomado por los terceristas en Barruelo. Así, sobre la nacionalización se proponía: "Que se nacionalice todo el suelo nacional imponiendo un impuesto directo sobre su valor, confiscando las rentas actuales en beneficios de las cargas del Tesoro y abolición de todos los impuestos que gravan el consumo y el trabajo". En materia de relaciones internacionales, e incluyéndose en el sector minoritario, no había duda: "Que la Unión General ingrese en la Tercera Internacional lo más pronto posible". Memoria y orden del día del XIV Congreso ordinario. Madrid, 1920.

${ }^{20}$ Datos procedentes de Memorias del XIV y XV congresos (junio de 1920 y noviembre de 1922) y El Socialista, 17 de diciembre de 1923 .
} 
y prestaciones laborales) $)^{21}$.

A ello se sumó una circunstancia que no debemos dejar de citar: el compromiso abiertamente comunista tomado por el relevante sindicalista José Calleja.

Destacado dirigente del SOMA y máximo exponente del influjo ugetista en la cuenca del Aller, José Calleja era de Villamanín. Manteniendo permanente contacto con las cuencas leonesas, merced a ser uno de los más activos propagandistas en el periodo que estamos analizando, su carisma de viejo luchador por los derechos de los trabajadores era muy alto. Al abandonar el SOMA y escorar hacia el tercerismo el impacto entre parte de la afiliación leonesa debió ser tremendo.

Atendiendo a las número de agrupaciones y afiliados, el Minero Castellano vio empequeñecer sus cifras entre 1920 y 1922 (ver tabla IV). En la cuenca de Gordón, máximo valuarte de la Unión en la provincia, se pasó de 1.555 a 509 afiliados; las cuencas orientales sólo recuperarían un peso destacado con la constitución, ya en mayo 1923, de las secciones del Sindicato Minero Castellano en Cistierna, Sabero y Olleros.

No sucedió lo mismo en las cuencas orientales, sobre todo en Laciana. Allí realmente se impidió que la crisis de afiliación produjese un hundimiento todavía mayor. La apertura de explotaciones en las concesiones de la MSP requería un aumento de mano de obra, y pese a que la presencia del interesado asociacionismo católico era evidente, la Unión consiguió establecerse de forma consistente.

La sección de San Miguel, constituida en febrero de 1920, siguió creciendo en la etapa crítica, llegando a los 120 adheridos. La de Villaseca, ya dentro del Minero Castellano, en los apenas cinco meses que van desde su asentamiento a la cuantificación de sus contingentes en el XV Congreso (de julio a noviembre de 1922), organizó a 322 mineros. Fulgencio Blasco y Daniel Rodríguez mantuvieron viva la influencia del ugetismo en Laciana hasta los años treinta.

La Federación Minera contó en adelante con unas bases fieles que respaldaban sin dudar las iniciativas de sus dirigentes. El peso numérico

\footnotetext{
21 Ver "El Trabajo en las minas de León”. El Socialista, 17 de octubre de 1923. En este artículo firmado por Agustín Marcos se hace un repaso histórico sobre la fluctuación de la producción y del rendimiento por trabajador en las minas de León en el periodo 1918-1923. Su confección responde a parte de la estrategia de la Federación Minera en el marco de las negociaciones que, con la mediación del Directorio Militar, se entablaron con la patronal del sector al poco del Golpe de Estado.
} 
era menor que años atrás, pero la cohesión era mayor, preparando a la organización para la representatividad que habría de tener a corto plazo.

Tabla VI. Movimiento huelguístico en la provincia de León ${ }^{22}$

\begin{tabular}{|c|c|c|c|c|c|c|c|c|c|c|c|}
\hline \multicolumn{4}{|c|}{1921} & \multicolumn{4}{|c|}{1922} & \multicolumn{4}{|c|}{1923} \\
\hline$(1)$ & $(2)$ & $(3)$ & $(4)$ & $(1)$ & $(2)$ & $(3)$ & $(4)$ & $(1)$ & $(2)$ & $(3)$ & $(4)$ \\
\hline 15 & 3702 & 3662 & 116267 & 13 & 2881 & 2060 & 52495 & 19 & 5762 & 4166 & 69693 \\
\hline
\end{tabular}

(1) Huelgas con datos completos.

(2) Obreros ocupados en los establecimientos con huelga.

(3) Huelguistas.

(4) Jornadas perdidas.

Efectivamente, ante el golpe militar de Primo de Rivera el 13 de septiembre de 1923 la Federación Minera asumió un protagonismo fundamental. El Jefe del Directorio Militar intuyó la posibilidad de contar con el apoyo tácito de la Unión General de Trabajadores. En una entrevista que mantuvo con Manuel Llaneza el 2 de octubre se sentaron las bases del acuerdo, aunque de manera oficial sólo trascendiese el simple trato de temas laborales en Asturias.

La Unión, a rebufo en este aspecto de la Federación Minera, reactualizó la vieja política oportunista, participando en la gestión de diversos organismos oficiales, además de asegurar una "paz social" necesaria para el régimen. Como contrapartida se hizo con lazos exclusivos de relación con la Dictadura que proporcionaron su monopolio de la representación obrera: la CNT estaba fuera de la Ley y los sindicatos católicos vieron cortado su grifo de financiación y tendieron a desaparecer al no eran útiles para la patronal debido al compromiso de la Unión.

22 Anuario Estadístico de España. 1922-1923 y 1930. Las cifras recogidas son una mera indicación de las tendencias, ya que al ser estadísticas oficiales, que sólo reseñaban "datos completos", no incluyen parte de la conflictividad laboral real; no obstante, su utilidad no deja de ser válida. 
